\title{
Femoral Periprosthetic Fractures after Total Knee Arthroplasty: New Surgically Oriented Classification with a Review of Current Treatments
}

\author{
Seung Joon Rhee, $\mathrm{MD}^{1}$, Jae Young Cho, $\mathrm{MD}^{2}$, Yoon Young Choi, $\mathrm{MD}^{3}$, Takeshi Sawaguchi, $\mathrm{MD}^{4}$, and \\ Jeung Tak Suh, MD ${ }^{1}$ \\ ${ }^{1}$ Department of Orthopedic Surgery, Biomedical Research Institute, Pusan National University Hospital, Busan; ${ }^{2}$ Department of Orthopedic Surgery, Haeundae \\ Bumin Hospital, Busan; ${ }^{3}$ Department of Diagnostic Radiology, Pusan National University Yangsan Hospital, Yangsan, Korea; ${ }^{4}$ Department of Orthopedics and Joint \\ Reconstructive Surgery, Toyama Municipal Hospital, Toyama, Japan
}

\begin{abstract}
Purpose: As the number of total knee arthroplasties (TKAs) increases, the incidence of femoral periprosthetic fractures after TKA is also increasing. This review aimed to suggest a new surgically oriented classification system for femoral periprosthetic fractures.

Methods: We investigated the classifications, and current treatment trends for femoral periprosthetic fractures after TKA by means of a thorough review of the relevant literature.

Results: Numerous studies reported good results of surgical treatment with modern fixatives including locking compression plates and retrograde intramedullary nails. However, few classifications of femoral periprosthetic fractures reflect the recent developments in surgical treatment.

Conclusions: We recommend that surgical management be considered the first-line treatment for femoral periprosthetic fractures after TKA. Our new classification will help in deciding the surgical treatment option for femoral periprosthetic fractures after TKA.
\end{abstract}

Keywords: Femur, Periprosthetic fracture, Arthroplasty, Classification, Plate, Osteosynthesis

\section{Introduction}

Femoral periprosthetic fractures are among the serious postoperative complications after total knee arthroplasty (TKA). Along with the increasing number of TKAs and the extending longevity of patients after TKA, the incidence of femoral periprosthetic fractures is also increasing ${ }^{1-9)}$. Proper management and

Received June 4, 2017; Revised (1st) July 4, 2017; (2nd) July 28, 2017;

Accepted August 3, 2017

Correspondence to: Seung Joon Rhee, MD

Department of Orthopedic Surgery, Pusan National University Hospital, 179 Gudeok-ro, Seo-gu, Busan 49241, Korea

Tel: +82-51-240-7248, Fax: +82-51-247-8395

E-mail: rheefury@naver.com

Source of funding: This work was supported by clinical research grant from Pusan National University Hospital in 2017.

This is an Open Access article distributed under the terms of the Creative Commons Attribution Non-Commercial License (http://creativecommons.org/licenses/by-nc/4.0/) which permits unrestricted non-commercial use, distribution, and reproduction in any medium, provided the original work is properly cited. healing of femoral periprosthetic fractures is essential because of the profound influence of these fractures on the prognosis and quality of life of patients ${ }^{6,10,11)}$. However, the treatment of femoral periprosthetic fractures is still challenging owing to several reasons. The primary concern is the advanced age of patients, which results in osteoporotic bones. Stable fixation of the fracture is technically difficult because of sparse bone stock with poor bone quality. Joint instability occurs in cases with collateral ligament injury complicating the fracture, which occasionally necessitates revision arthroplasty with a constrained-type implant. To our knowledge, despite several attempts to classify femoral periprosthetic fractures, a classification that is directly relevant to current surgical treatment strategies has not yet been suggested ${ }^{4,12-18)}$.

Therefore, in this review, we intended to suggest a new surgically oriented classification system for femoral periprosthetic fractures based on a thorough review of precedent classifications and various recent surgical treatment results. 


\section{Risk Factors}

The most important and well-recognized predisposing factor to femoral periprosthetic fractures after TKA is osteoporosis ${ }^{19-21)}$, which is primarily related to the advanced age of patients who undergo TKA. Chronic corticosteroid use and rheumatoid arthritis also contribute to osteoporotic changes ${ }^{1,15}$. Prosthesisrelated factors, including the presence of stress risers, focal osteolysis, stiff knee, and previous revision arthroplasty, also increase the risk ${ }^{1,15,20)}$. Among these factors, anterior notching of the femur has been well proven to increase the risk for femoral periprosthetic fractures after TKA ${ }^{1,15,20,22,23)}$. Neurological abnormalities including poliomyelitis, Parkinson's disease, and cerebral palsy are also known to be potential risk factors ${ }^{1,15)}$.

\section{Classifications}

Since the first suggestion of a classification for supracondylar femoral fractures by Neer et al. ${ }^{16)}$, various classifications from many researchers have been suggested concerning periprosthetic fractures after TKA (Table 1). Those that are primarily concerned with the displacement of fractured fragments can be categorized as the first-generation classifications. Neer et al. ${ }^{16)}$ classification described supracondylar femoral fractures according to the direction of the displacement, thus reflecting the direction of the external force and injury of the extensor mechanism. DiGioia and Rubash ${ }^{14)}$ clarified the definition of periprosthetic fractures and graded the severity of comminutions, and their classification mainly considered the possibility of closed reduction. Chen et al. ${ }^{13)}$ simplified the precedent classifications into displaced and undisplaced types. These first-generation classifications were helpful in deciding whether the fracture was suitable for conservative treatment or operative treatment. However, a specific relationship between the fracture type and the choice of surgical technique could not be established with the first-generation classifications. The second generation of classifications for femoral periprosthetic fractures was started by Rorabeck and Taylor ${ }^{17)}$. They performed a detailed review of the various surgical treatment options for displaced-type fractures and additionally suggested revision arthroplasty as a treatment for periprosthetic fractures with an unstable prosthesis. Their treatment algorithm remains influential thus far as an important guideline for the treatment of periprosthetic fractures. Su et al. ${ }^{18)}$ classified femoral periprosthetic fractures into three types according to the fracture location relative to the femoral component. Their classification primarily considered the indication of intramedullary nails (an- tegrade and retrograde). They opposed nonsurgical treatment, which was recommended for nondisplaced femoral periprosthetic fractures in the precedent literature, except for patients who are medically unfit to tolerate surgery. Kim et al. ${ }^{15)}$ considered the volume and density of the distal bone stock, component fixation status, and fracture reducibility as important factors in categorizing femoral periprosthetic fractures. The classification of Backstein et al. ${ }^{12)}$ basically divided femoral periprosthetic fractures into two types according to the feasibility of retrograde intramedullary nailing (RIMN), and added two more qualifiers according to the stability of prosthesis and quality of the bone stock. Frenzel et al. ${ }^{4)}$ added the time point of fracture occurrence to factors including fracture type, prosthesis stability, and bone quality. Those second-generation classifications elucidated femoral periprosthetic fractures after TKA mainly from the surgical standpoint. The development of novel operative techniques and fixatives seems to have led to a changing trend in the treatment and classification systems.

\section{Literature Review}

Although decades have passed since the earliest reports on femoral periprosthetic fractures, their prognostic improvement is still obscure. Periprosthetic fractures were identified as a factor leading to decreased survival by Streubel et al. ${ }^{11)}$ in 2011, and mortality rates of $14 \%$ and $18.6 \%$ in 3 and 12 months after periprosthetic fractures following TKA, respectively, were reported in $2014^{10)}$. The fact that the quality of life and joint function in patients with periprosthetic fractures after TKA was significantly decreased and only $20 \%$ of the patients can mobilize without further assistance ${ }^{6}$ may be possible explanations.

Conservative treatment established an axis for the management of nondisplaced fractures during the era of the first-generation classifications ${ }^{13,14,16)}$. A conservative treatment option was valuable during that period when the treatment results after surgical reduction were not fairly reliable or prevalent over those of conservative treatment ${ }^{19,20,24,25)}$. A number of operative treatment methods were suggested for displaced femoral periprosthetic fractures (Lewis and Rorabeck type II equivalent ${ }^{17}$ ) in that era. Angled blade plating, dynamic condylar screw fixation, and conventional non-locking plating are well known internal fixation methods. However, with the reports on the superior clinical results of the angular stable locking compression plate (LCP) and RIMN over those conventional fixation methods, the surgical treatment has rapidly changed since the mid-2000s ${ }^{26-28)}$. Althausen et al. ${ }^{26)}$ performed a comparative study on four different surgical treatment 


\section{Rhee et al. Femoral Periprosthetic Fracture after TKA}

Table 1. Classification Systems for Femoral Periprosthetic Fractures after Total Knee Arthroplasty

\begin{tabular}{|c|c|c|c|c|}
\hline Author & Year & Type or group & Description & Special consideration \\
\hline \multirow[t]{5}{*}{ Neer et al. ${ }^{16)}$} & \multirow[t]{5}{*}{1967} & Group I & Impacted or minimally displaced & Injury mechanism \\
\hline & & Group II & Displacement $>1 \mathrm{~cm}$ & Direction of external force \\
\hline & & A & Medially displaced condyles & Extensor mechanism continuity \\
\hline & & B & Laterally displaced condyles & \\
\hline & & Group III & Meta-diaphyseal comminution & \\
\hline \multirow[t]{3}{*}{$\begin{array}{l}\text { DiGioia and } \\
\text { Rubash }^{14)}\end{array}$} & \multirow[t]{3}{*}{1991} & Group I & $\begin{array}{l}\text { Extra-articular, undisplaced ( }<5 \mathrm{~mm} \text { displacement } \\
\text { and }<5^{\circ} \text { angulation) }\end{array}$ & \multirow{3}{*}{$\begin{array}{l}\text { Defined PPFx.: any fx. of the distal femur } \\
\text { within } 15 \mathrm{~cm} \text { of the TKA joint line or within } \\
5 \mathrm{~cm} \text { of the stem } \\
\text { Defined the severity of comminution: } \\
\text { Minimal: } \geq 50 \% \text { cortical contact } \\
\text { Severe: }<50 \% \text { cortical contact }\end{array}$} \\
\hline & & Group II & $\begin{array}{l}\text { Extra-articular, displaced ( }>5 \mathrm{~mm} \text { displacement or } \\
>5^{\circ} \text { angulation) }\end{array}$ & \\
\hline & & Group III & $\begin{array}{l}\text { Severely displaced (loss of cortical contact) or } \\
\text { angulated }\left(>10^{\circ}\right) \text {; may have intercondylar or } \\
\text { T-shaped component }\end{array}$ & \\
\hline \multirow[t]{2}{*}{ Chen et al. ${ }^{13)}$} & \multirow[t]{2}{*}{1994} & Type I & Nondisplaced & \multirow{2}{*}{$\begin{array}{l}\text { Helped in decision making between } \\
\text { conservative Tx. and operative Tx. }\end{array}$} \\
\hline & & Type II & Displaced and/or comminuted & \\
\hline \multirow{3}{*}{$\begin{array}{l}\text { Rorabeck and } \\
\text { Taylor }^{17)}\end{array}$} & \multirow[t]{3}{*}{1999} & Type I & Undisplaced fx., stable prosthesis & \multirow{3}{*}{$\begin{array}{l}\text { Suggested a Tx. algorithm with detailed surgical } \\
\text { options }\end{array}$} \\
\hline & & Type II & Displaced fx., stable prosthesis & \\
\hline & & Type III & Displaced or undisplaced fx., unstable prosthesis & \\
\hline \multirow[t]{3}{*}{ Su et al. ${ }^{18)}$} & \multirow[t]{3}{*}{2004} & Type I & Fx. promimal to femoral component & \multirow{3}{*}{$\begin{array}{l}\text { Guided operative treatment options according } \\
\text { to the fracture level } \\
\text { Scrutinized the feasibility of retrograde nailing }\end{array}$} \\
\hline & & Type II & $\begin{array}{l}\text { Fx. Originating from the femoral component and } \\
\text { extending proximally }\end{array}$ & \\
\hline & & Type III & $\begin{array}{l}\text { Any part of fx. line is distal to the upper edge of the } \\
\text { anterior flange }\end{array}$ & \\
\hline \multirow[t]{5}{*}{ Kim et al. ${ }^{15)}$} & \multirow[t]{5}{*}{2006} & Type I & & \multirow[t]{5}{*}{ Included the issue of bone stock quality } \\
\hline & & A & $\begin{array}{l}\text { Reducible fx., good distal bone stock, stable } \\
\text { component }\end{array}$ & \\
\hline & & B & $\begin{array}{l}\text { Irreducible fx., good distal bone stock, stable } \\
\text { component }\end{array}$ & \\
\hline & & Type II & Unstable component & \\
\hline & & Type III & Unstable component, poor bone stock & \\
\hline \multirow[t]{2}{*}{ Backstein et al. $^{12)}$} & \multirow[t]{2}{*}{2007} & Type F1 & $\begin{array}{l}\text { Distal fx. fragment provides adequate bone for } \\
\text { retrograde nail locking }\end{array}$ & \multirow{2}{*}{$\begin{array}{l}\text { Additional qualifiers } \\
\text { stable/loose prosthesis } \\
\text { good/poor bone stock } \\
\text { Retrograde nail feasibility }\end{array}$} \\
\hline & & Type F2 & $\begin{array}{l}\text { Distal fx. does not provide adequate bone for } \\
\text { retrograde nail locking }\end{array}$ & \\
\hline Marsh et al. ${ }^{56)}$ & 2007 & $33-A 1-3$ & Distal femur extra-articular fx. & $\begin{array}{l}\text { New unified classification system } \\
\text { (Müller-AO+OTA classification) } \\
\text { Anatomical classification }\end{array}$ \\
\hline Frenzel et al. ${ }^{4)}$ & 2015 & $3 \mathrm{KP} 3$ & $\begin{array}{l}\text { Distal femur fx. above the cemented knee } \\
\text { arthroplasty }\end{array}$ & $\begin{array}{l}\text { Fracture type } \\
\text { Prosthesis stability } \\
\text { Time point of fx. occurrence } \\
\text { Bone structure }\end{array}$ \\
\hline
\end{tabular}

PPFx.: periprosthetic fracture, fx.: fracture, Tx.: treatment.

methods in 12 patients and reported that loss of fixation and varus angulation owing to limited distal fixation were not observed with the less invasive stabilization system by using LCP. Ricci et al. $^{28)}$ and Fulkerson et al. ${ }^{27)}$ consecutively reported excellent union rates with LCP for femoral periprosthetic fractures. Thereafter, numerous recent studies reported the excellent clinical results of 
LCP and RIMN as the mainstream surgical treatment modalities for femoral periprosthetic fractures ${ }^{11,27-46)}$. Each of the two fixation methods has its own advantages over the other and has different indications originating from their unique fixation mechanism. As an LCP can be inserted submuscularly through a minimally invasive approach with minimum disruption of the fracture healing microenvironments, relatively preserved periosteal blood supply and callus formation is advantageous in the treatment of comminuted metaphyseal fractures. Moreover, multiple angular stable locking head screws enable maximum purchase of even very distal small fragments and confer a sufficient amount of relative stability, which is required for fracture healing. RIMN was also introduced as a soft-tissue-friendly and minimally invasive internal fixation method in almost the same period as LCP. RIMN has some biomechanical advantages over $\mathrm{LCP}^{44)}$. The fact that the retrograde intramedullary nail is coaxially implanted along the anatomical axis of the femur confers this implant the stiffest construct under axial loading with an extremely short moment arm. Moreover, the relatively centered position of the implant from the lateral and medial cortex of the femur provides more stability during ambulation, especially in patients with medial-column comminution, than does the unilateral LCP. However, the application of RIMN is restricted to certain cases. In the femoral component with a closed intercondylar box design, the entry portal is blocked. Even with the open box design, the dimension of the opening is sometimes insufficient to permit the nail insertion in RIMN $^{18)}$. As RIMN was developed and used in the same period as LCP, and both treatment methods had similar fracture healing biomechanism, many comparative studies were performed. Wick et al. reported the superior mechanical properties of LCP in fractures with small distal fragments ${ }^{47}$. Large et al. ${ }^{48)}$ compared an LCP group versus a conventional plate and RIMN group, and reported superior results with LCP. Hou et al. ${ }^{32)}$ reported three nonunions and three malunions in 34 LCP cases versus one infectious nonunion and two malunions in 18 RIMN cases. Gondalia et al ${ }^{40)}$ found no significant differences in clinical results, time to union, complication rate, or postoperative range of motion. They also found a trend toward a higher nonunion rate with LCP and a higher re-fracture rate with RIMN. Meneghini et al. ${ }^{34)}$ stated that despite a greater quantity of screws in the distal fragment, the failure rate of LCP was twice that of RIMN, based on the results of their relatively large comparative study. Park and Lee ${ }^{35)}$ found no significant difference in the comparison of 20 RIMN cases versus 21 LCP cases; however, they stated that angular stable plating was a better treatment option for very low supracondylar fractures.

Concerning the treatment of far distal femoral periprosthetic fractures, Sanders et al. ${ }^{46)}$ first documented a trial of bicortical double plating with conventional plates. Thereafter, Streubel et al. ${ }^{11)}$ proved that unilateral LCP alone can fix far distal fractures, and a case report on bilateral bicortical double plating followed ${ }^{49}$. Kim et al. ${ }^{33)}$ scrutinized the theoretical and clinical background of double plating and reported a $93.2 \%$ union rate in 32 cases. Herrera et al. ${ }^{50)}$ conducted a systematic review of 415 femoral periprosthetic fractures above a TKA in 2008. According to their results, LCP was superior to conventional plating in terms of the nonunion rate and the requirement for a secondary procedure. However, RIMN was superior to LCP in the nonunion and fixation failure rates. They stated that the treatment of femoral periprosthetic fractures after TKA is evolving toward minimally invasive percutaneous plate osteosynthesis and RIMN and away from extensive approaches and rigid anatomic fixation methods. The largest comparison between LCP and RIMN was conducted in a systematic review by Ebraheim et al. ${ }^{3}$. According to their research, the overall treatment success rate of LCP and RIMN was $87 \%$ and $84 \%$, respectively, in Lewis and Rorabeck type II fractures. Among the nine articles they analyzed, five articles showed no overall advantage to either method, three articles supported the superiority of LCP, and one article favored nailing. Lower overall complication rate was reported with LCP. The most recent meta-analysis was conducted by Shin et al. ${ }^{37)}$ on eight randomized controlled trials. In their analysis, the postoperative Knee Society Score, time to union, nonunion rate, and revision requirement were not significantly different between LCP and RIMN. They stated that RIMN had biomechanical advantages over LCP in resisting external loads and that LCP might be preferable to RIMN owing to the limitations of RIMN in clinical practice.

Finally, on the basis of the two main pillars (LCP and RIMN) of femoral periprosthetic fractures, newer surgical techniques, including double plating, orthogonal plating, or far cortical locking, are also emerging ${ }^{51)}$.

\section{New Classification}

Although several classifications of femoral periprosthetic fractures by a number of authors have been proposed, as aforementioned, few reflect the recent developments in surgical treatment, to our knowledge. Therefore, we developed a new classification system that is directly relevant to the current surgical treatment options (Fig. 1).

Type I fractures are simple transverse two-part fractures that involve fracture lines directly connected to the anterior flange of the femoral component and extend upon it. As these fractures 
have sufficient and stable distal bone stock to contain multiple distal fixatives, both RIMN and unilateral LCP can be used according to the suitability of the intercondylar box of a total knee implant.

Type II fractures have an oblique or reverse-oblique fracture line involving the anterior flange of the femoral component. These fractures include an inferomedially or inferolaterally beaked proximal fragment and a superolaterally or superomedially peaking remnant distal fragment, respectively, with more or less comminution. These fractures are not suitable for RIMN and can be treated with unilateral LCP on the basis of a relatively preserved medial column support.

Type III fractures are relatively less comminuted fractures well below the anterior flange or medially comminuted fractures. Owing to the small distal bone stock or lack of a medial column support, the distal fixation provided by unilateral LCP is insufficient to maintain stable fixation in this type of fractures. Bicortical double plating with an additional medial plate is applicable in this case.

Type IV fractures are transverse fractures of the femur shaft occurring around the tip of the stem extension attached to the revision implant. These fractures do not provide sufficient distal bone stock even for LCP, and most of the sagittal dimension is blocked by the revision implant. A periarticular polyaxial plate with a variable-angle locking screw will likely be the last resort for internal fixation.

Type V fractures can be described as "shattered" distal fragments that do not have any recognizable main fragment with an unstable implant. Distal femoral arthroplasty, tumor prosthesis, or revision arthroplasty with an allograft-prosthesis composite graft are the possible choices for prompt surgical treatment.

\section{Treatment}

On the basis of continuing reports of superior treatment results with LCP or RIMN, we believe that conservative treatment should no longer be an option for the treatment of femoral periprosthetic fractures, even nondisplaced fractures ${ }^{29-38)}$. Considering the demographic background of patients including their advanced age and rapid deterioration of general condition due to prolonged bed rest, conservative treatment should be removed from the directory of treatment options for femoral periprosthetic fractures, except for unavoidable cases.

According to our classification, both LCP and RIMN can be applied to treat type I fractures (Su type II equivalent ${ }^{18)}$ ) with sufficient distal bone stock, except for a closed-box-type femoral component. It means that LCP or RIMN is available in type I fracture according to the specific environment of a fracture case. Height of the anterior flange and shape of the intercondylar box is different in between every TKA femoral components. Different starting points of the fracture can leave unequal amount of distal bone stock to be purchased even if all the fractures in type I are originating from the anterior flange impact. So, the operators have to make a decision about the implant. Type I fracture is the only femoral periprosthetic fracture type with nail (specifically, RIMN) applicability in this new classification. We considered femoral fractures occurring well above the anterior flange of the femoral component (Su type I equivalent ${ }^{18)}$ ) separately from femoral periprosthetic fractures, as the fracture might not be biomechanically generated by the direct impact of the prosthesis but has restrictions in the fixation method owing to the existence of the prosthesis. In our perspective, those are not "genuine" femoral periprosthetic fractures. Antegrade intramedullary nailing, which
Type I

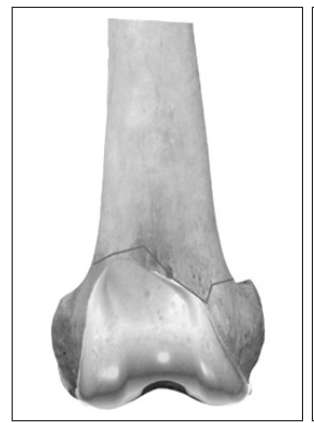

Type II

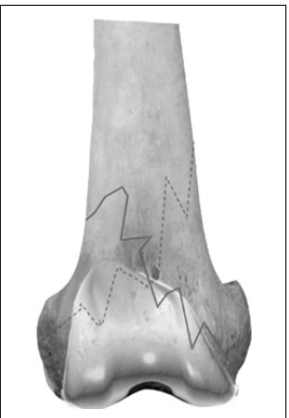

Type III

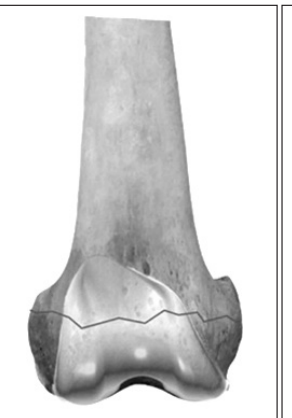

Type IV

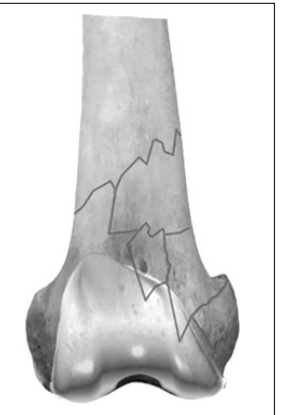

\section{Trang}

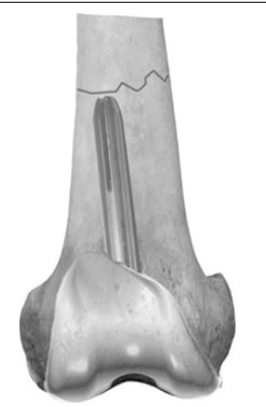

Type V

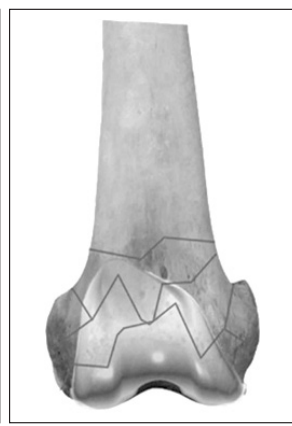

Fig. 1. Anteroposterior views for femoral periprosthetic fracture classification. Type I: simple transverse two-part fracture which involves fracture lines directly connected to the anterior flange of the femoral component and extending upon it. Type II: fracture with an oblique or reverse-oblique fracture line involving the anterior flange of the femoral component. Type III: relatively less comminuted fracture well below the anterior flange or medially comminuted fracture. Type IV: transverse fracture occurring around the tip of the stem extension attached to the revision implant. Type V: fracture with "shattered" distal fragments that do not have any recognizable main fragment with an unstable implant. 
was mentioned as a surgical treatment method in some other literature reports, was not included in our considerations for such a reason.

For our type II fractures, unilateral LCP will be a better surgical treatment option than RIMN (Fig. 2). In type II fractures, the distal interlocking screws of RIMN will likely be purchasing different fragments of the fracture, which will function similarly to the interfragmentary screw. If the situation necessitates indirect bone union, the use of an interfragmentary screw will retard union. Even if fine reduction of the fragment were achieved, the number and compressive force of distal interlocking screws in RIMN are insufficient to maintain the stability of the construct. With laterally or medially beaked distal bone fragments, LCP can hold the fragment better with multiple angular stable locking screws, and the length of screw insertion can be adjusted according to the intended fracture healing mechanism.

Fractures with scant distal bone stock (Su type III equivalent ${ }^{18)}$ ) or a comminuted medial column are difficult to maintain stability with unilateral LCP. Fractures with scant distal bone stock provide insufficient bone stock for distal locking screws of unilateral LCP, and medialized impact through a comminuted medial column is enough to collapse the construct, as Sanders et al. ${ }^{46}$ previously warned. Bicortical double LCP can help in managing those situations (Fig. 3). Addition of medial LCP enables doubling the number of proximal and distal screws and resisting medialized impact. Kim et al. ${ }^{33)}$ reported a 93.2\% union rate in their study concerning 32 Su type III fractures with 21 very distal fragments $^{18)}$.

There are few remaining choices for internal fixation of femoral periprosthetic fractures occurring above the stemmed revision implant. Considering the coarse bone stock around the metaphyseal region and the primary load bearing of the stem, diaphyseal fractures adjacent to the stem tip will occur rather than metaphyseal fractures in this situation. A polyaxial locking plate such as
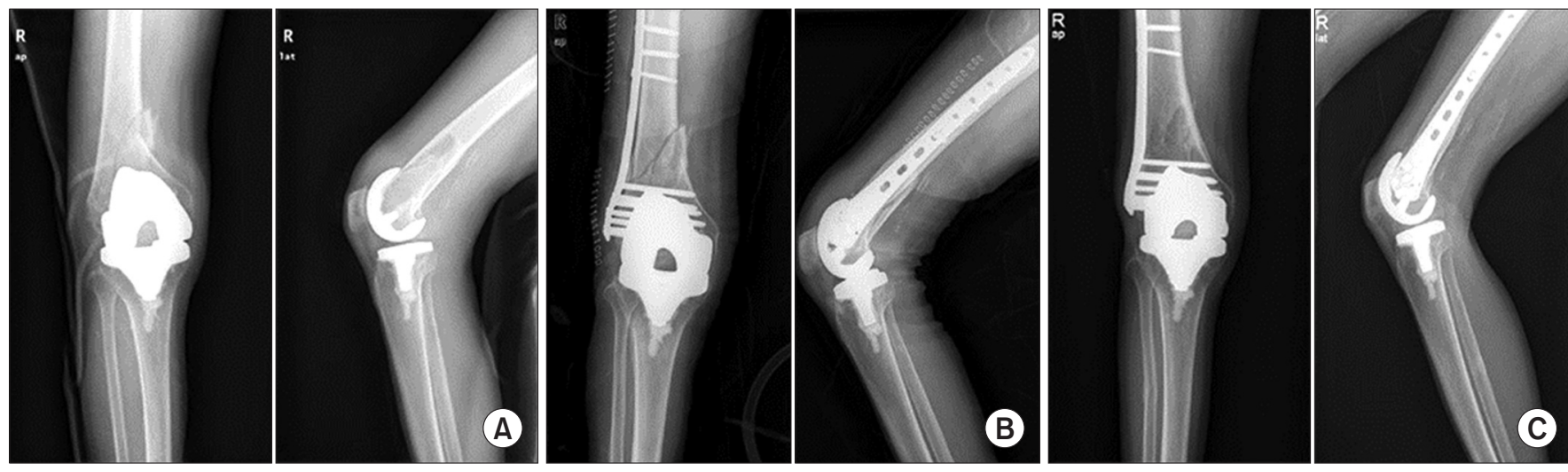

Fig. 2. (A) Preoperative radiographs of a femoral periprosthetic fracture with a reverse-oblique fracture line involving the anterior flange of the femoral component. (B) This fracture was treated by a unilateral locking compression plate. (C) Fracture union with remodeling is evident on the last follow-up radiographs.
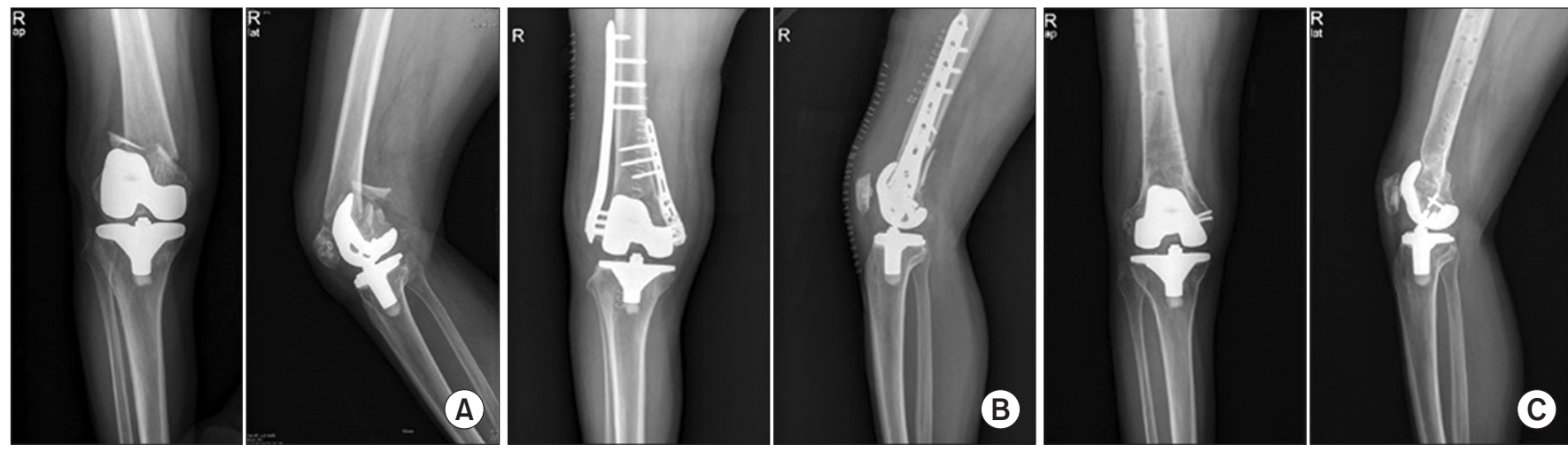

Fig. 3. (A) Preoperative radiographs of a femoral periprosthetic fracture with relatively less comminuted small distal bone stock well below the anterior flange. (B) This fracture was treated by bicortical double locking compression plates (LCPs). (C) The LCPs were removed after complete union of the fracture. 

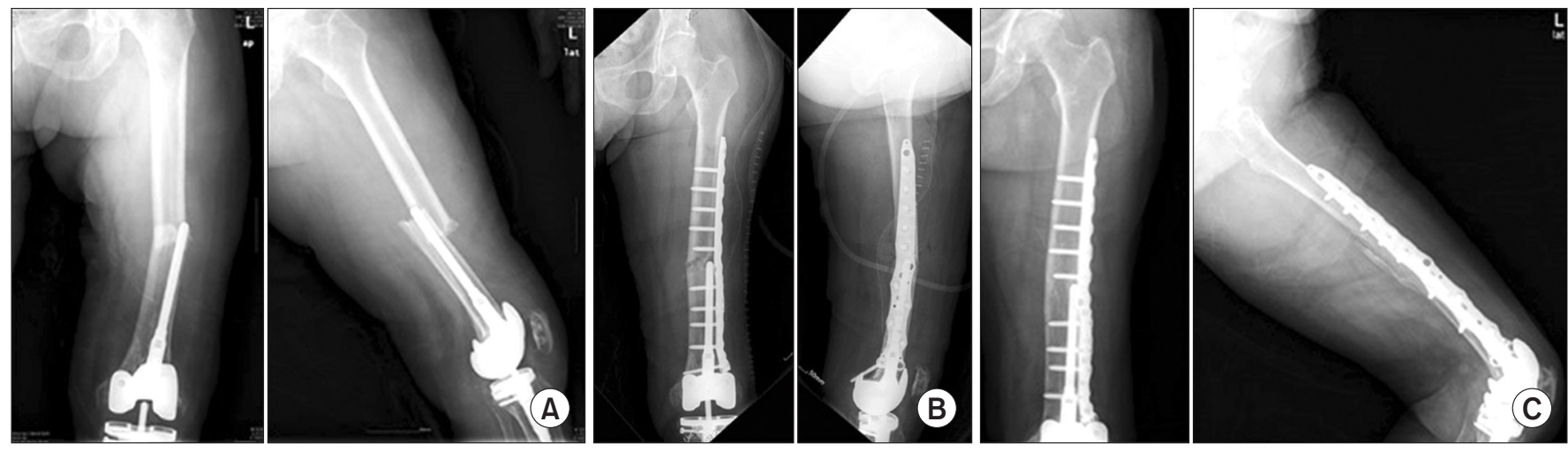

Fig. 4. (A) Preoperative radiographs of a femoral periprosthetic fracture that occurred above the tip of the stem extension attached to the revision implant. (B) This fracture was treated by a precontoured polyaxial locking plate with allogenous bone graft. (C) Union was achieved 6 months after the surgery.

NCB (Non-contact Bridging Plate; Zimmer Inc., Winterthur, Switzerland) can be used in this type of fractures (Fig. 4). The $\mathrm{NCB}$ plate utilizes a $30^{\circ}$ polyaxial locking screw mechanism to maximize the chance of scant bone stock purchase despite the space-occupying stem extension or the revision implant. Polyaxial screws can be used both as a locking screw and a compression screw according to the situation, and one screw resists a load of $225 \mathrm{~N}$ at a distance of $25 \mathrm{~mm}$ from the plate ${ }^{39)}$. Erhardt et al. ${ }^{39)}$ reported excellent outcomes of NCB in their study on 12 Rorabeck and Taylor ${ }^{17)}$ type II fractures. Ruchholtz et al. ${ }^{36)}$ mentioned that a locking plate was the actual treatment of choice in a periprosthetic fracture with a stable intramedullary stem or implant, and reported that they could set a minimum of 3 and a mean of 5.4 bicortical screws around a stem with NCB.

For fractures with an unstable implant or extreme comminution of the distal fragment, revision arthroplasty has been mentioned in the literature since the report of Rorabeck and Taylor ${ }^{17)}$. However, the conventional revision arthroplasty system is insufficient to treat this type of femoral periprosthetic fractures. Often, there is a cluster of shattered bones and it is amorphous. The reality of the type $\mathrm{V}$ situation makes it nearly impossible to preserve and fix the bone stock and to perform direct revision arthroplasty simultaneously. If the patient requires prompt surgical management, revision arthroplasty in this context means an implant that can replace the lost bone stock, attaching to the host bone and functioning as a joint altogether. Distal femoral replacement, tumor prosthesis, and structural allograft prosthetic composite are included in the revision arthroplasty methods. Recently, although some studies reported considerable treatment results with distal femoral arthroplasty in this type $\mathrm{V}$ situation ${ }^{52-55)}$, revision arthroplasty is likely to be a salvage operation at best.

\section{Conclusions}

Femoral periprosthetic fractures after TKA still pose a challenge in terms of treatment and lack a standardized classification system that is based on surgical treatment. LCP and RIMN are the two main surgical options with proven efficiency. Our new classification will help in deciding the surgical treatment option for femoral periprosthetic fractures after TKA.

\section{Conflict of Interest}

No potential conflict of interest relevant to this article was reported.

\section{References}

1. Agarwal S, Sharma RK, Jain JK. Periprosthetic fractures after total knee arthroplasty. J Orthop Surg (Hong Kong). 2014; 22:24-9.

2. Drew JM, Griffin WL, Odum SM, Van Doren B, Weston BT, Stryker LS. Survivorship after periprosthetic femur fracture: factors affecting outcome. J Arthroplasty. 2016;31:1283-8.

3. Ebraheim NA, Kelley LH, Liu X, Thomas IS, Steiner RB, Liu J. Periprosthetic distal femur fracture after total knee arthroplasty: a systematic review. Orthop Surg. 2015;7:297-305.

4. Frenzel S, Vecsei V, Negrin L. Periprosthetic femoral fractures: incidence, classification problems and the proposal of a modified classification scheme. Int Orthop. 2015;39:1909-20.

5. Lizaur-Utrilla A, Miralles-Muñoz FA, Sanz-Reig J. Functional outcome of total knee arthroplasty after periprosthetic distal femoral fracture. J Arthroplasty. 2013;28:1585-8.

6. Mardian S, Schaser KD, Scheel F, Gruner J, Schwabe P. Qual- 
ity of life and functional outcome of periprosthetic fractures around the knee following knee arthroplasty. Acta Chir Orthop Traumatol Cech. 2015;82:113-8.

7. Roderer G, Gebhard F, Scola A. Principles of management of periprosthetic fractures. Unfallchirurg. 2016;119:177-84.

8. Singh SP, Bhalodiya HP. Outcome and incidence of periprosthetic supracondylar femoral fractures in TKA. Indian J Orthop. 2013;47:591-7.

9. von Matthey F, Ruchholtz S, Biberthaler P, Hanschen M. Osteosynthesis after periprosthetic fractures of the knee joint. Unfallchirurg. 2016;119:288-94.

10. Shields E, Behrend C, Bair J, Cram P, Kates S. Mortality and financial burden of periprosthetic fractures of the femur. Geriatr Orthop Surg Rehabil. 2014;5:147-53.

11. Streubel PN, Gardner MJ, Morshed S, Collinge CA, Gallagher B, Ricci WM. Are extreme distal periprosthetic supracondylar fractures of the femur too distal to fix using a lateral locked plate? J Bone Joint Surg Br. 2010;92:527-34.

12. Backstein D, Safir O, Gross A. Periprosthetic fractures of the knee. J Arthroplasty. 2007;22(4 Suppl 1):45-9.

13. Chen F, Mont MA, Bachner RS. Management of ipsilateral supracondylar femur fractures following total knee arthroplasty. J Arthroplasty. 1994;9:521-6.

14. DiGioia AM 3rd, Rubash HE. Periprosthetic fractures of the femur after total knee arthroplasty: a literature review and treatment algorithm. Clin Orthop Relat Res. 1991;(271):13542.

15. Kim KI, Egol KA, Hozack WJ, Parvizi J. Periprosthetic fractures after total knee arthroplasties. Clin Orthop Relat Res. 2006;446:167-75.

16. Neer CS 2nd, Grantham SA, Shelton ML. Supracondylar fracture of the adult femur: a study of one hundred and ten cases. J Bone Joint Surg Am. 1967;49:591-613.

17. Rorabeck $\mathrm{CH}$, Taylor JW. Periprosthetic fractures of the femur complicating total knee arthroplasty. Orthop Clin North Am. 1999;30:265-77.

18. Su ET, DeWal H, Di Cesare PE. Periprosthetic femoral fractures above total knee replacements. J Am Acad Orthop Surg. 2004;12:12-20.

19. Culp RW, Schmidt RG, Hanks G, Mak A, Esterhai JL Jr, Heppenstall RB. Supracondylar fracture of the femur following prosthetic knee arthroplasty. Clin Orthop Relat Res. 1987;(222):212-22.

20. Merkel KD, Johnson EW Jr. Supracondylar fracture of the femur after total knee arthroplasty. J Bone Joint Surg Am. 1986;68:29-43.
21. Yoo JD, Kim NK. Periprosthetic fractures following total knee arthroplasty. Knee Surg Relat Res. 2015;27:1-9.

22. Lesh ML, Schneider DJ, Deol G, Davis B, Jacobs CR, Pellegrini VD Jr. The consequences of anterior femoral notching in total knee arthroplasty: a biomechanical study. J Bone Joint Surg Am. 2000;82:1096-101.

23. Ritter MA, Thong AE, Keating EM, Faris PM, Meding JB, Berend ME, Pierson JL, Davis KE. The effect of femoral notching during total knee arthroplasty on the prevalence of postoperative femoral fractures and on clinical outcome. J Bone Joint Surg Am. 2005;87:2411-4.

24. Cain PR, Rubash HE, Wissinger HA, McClain EJ. Periprosthetic femoral fractures following total knee arthroplasty. Clin Orthop Relat Res. 1986;(208):205-14.

25. Figgie MP, Goldberg VM, Figgie HE 3rd, Sobel M. The results of treatment of supracondylar fracture above total knee arthroplasty. J Arthroplasty. 1990;5:267-76.

26. Althausen PL, Lee MA, Finkemeier CG, Meehan JP, Rodrigo JJ. Operative stabilization of supracondylar femur fractures above total knee arthroplasty: a comparison of four treatment methods. J Arthroplasty. 2003;18:834-9.

27. Fulkerson E, Tejwani N, Stuchin S, Egol K. Management of periprosthetic femur fractures with a first generation locking plate. Injury. 2007;38:965-72.

28. Ricci WM, Loftus T, Cox C, Borrelli J. Locked plates combined with minimally invasive insertion technique for the treatment of periprosthetic supracondylar femur fractures above a total knee arthroplasty. J Orthop Trauma. 2006;20: 190-6.

29. Gavaskar AS, Tummala NC, Subramanian M. The outcome and complications of the locked plating management for the periprosthetic distal femur fractures after a total knee arthroplasty. Clin Orthop Surg. 2013;5:124-8.

30. Ha CW, Shon OJ, Lim SW, Park KH. Minimally invasive plate osteosynthesis for periprosthetic distal femoral fractures after total knee arthroplasty. Knee Surg Relat Res. 2014; 26:27-32.

31. Hoffmann MF, Jones CB, Sietsema DL, Koenig SJ, Tornetta P 3rd. Outcome of periprosthetic distal femoral fractures following knee arthroplasty. Injury. 2012;43:1084-9.

32. Hou Z, Bowen TR, Irgit K, Strohecker K, Matzko ME, Widmaier J, Smith WR. Locked plating of periprosthetic femur fractures above total knee arthroplasty. J Orthop Trauma. 2012;26:427-32.

33. Kim W, Song JH, Kim JJ. Periprosthetic fractures of the distal femur following total knee arthroplasty: even very distal 
fractures can be successfully treated using internal fixation. Int Orthop. 2015;39:1951-7.

34. Meneghini RM, Keyes BJ, Reddy KK, Maar DC. Modern retrograde intramedullary nails versus periarticular locked plates for supracondylar femur fractures after total knee arthroplasty. J Arthroplasty. 2014;29:1478-81.

35. Park J, Lee JH. Comparison of retrograde nailing and minimally invasive plating for treatment of periprosthetic supracondylar femur fractures (OTA 33-A) above total knee arthroplasty. Arch Orthop Trauma Surg. 2016;136:331-8.

36. Ruchholtz S, El-Zayat B, Kreslo D, Bucking B, Lewan U, Kruger A, Zettl R. Less invasive polyaxial locking plate fixation in periprosthetic and peri-implant fractures of the femur: a prospective study of 41 patients. Injury. 2013;44:239-48.

37. Shin YS, Kim HJ, Lee DH. Similar outcomes of locking compression plating and retrograde intramedullary nailing for periprosthetic supracondylar femoral fractures following total knee arthroplasty: a meta-analysis. Knee Surg Sports Traumatol Arthrosc. 2017;25:2921-8.

38. Song SJ, Kim KI, Song WJ, Kim DK, Bae DK. Treatment of distal femur fractures with locking plates: Comparison of periprosthetic fractures above total knee arthroplasty and non-periprosthetic fractures. Acta Orthop Belg. 2014;80:38090.

39. Erhardt JB, Grob K, Roderer G, Hoffmann A, Forster TN, Kuster MS. Treatment of periprosthetic femur fractures with the non-contact bridging plate: a new angular stable implant. Arch Orthop Trauma Surg. 2008;128:409-16.

40. Gondalia V, Choi DH, Lee SC, Nam CH, Hwang BH, Ahn HS, Ong AC, Park HY, Jung KA. Periprosthetic supracondylar femoral fractures following total knee arthroplasty: clinical comparison and related complications of the femur plate system and retrograde-inserted supracondylar nail. J Orthop Traumatol. 2014;15:201-7.

41. Kolb K, Koller H, Lorenz I, Holz U, Marx F, Grützner P, Kolb $\mathrm{W}$. Operative treatment of distal femoral fractures above total knee arthroplasty with the indirect reduction technique: a long-term follow-up study. Injury. 2009;40:433-9.

42. Kolb W, Guhlmann H, Windisch C, Marx F, Koller H, Kolb K. Fixation of periprosthetic femur fractures above total knee arthroplasty with the less invasive stabilization system: a midterm follow-up study. J Trauma. 2010;69:670-6.

43. Kregor PJ, Hughes JL, Cole PA. Fixation of distal femoral fractures above total knee arthroplasty utilizing the Less Invasive Stabilization System (L.I.S.S.). Injury. 2001;32 Suppl 3: SC64-75.
44. Makinen TJ, Dhotar HS, Fichman SG, Gunton MJ, Woodside M, Safir O, Backstein D, Willett TL, Kuzyk PR. Periprosthetic supracondylar femoral fractures following knee arthroplasty: a biomechanical comparison of four methods of fixation. Int Orthop. 2015;39:1737-42.

45. Pressmar J, Macholz F, Merkert W, Gebhard F, Liener UC. Results and complications in the treatment of periprosthetic femur fractures with a locked plate system. Unfallchirurg. 2010;113:195-202.

46. Sanders R, Swiontkowski M, Rosen H, Helfet D. Doubleplating of comminuted, unstable fractures of the distal part of the femur. J Bone Joint Surg Am. 1991;73:341-6.

47. Wick M, Muller EJ, Kutscha-Lissberg F, Hopf F, Muhr G. Periprosthetic supracondylar femoral fractures: LISS or retrograde intramedullary nailing? Problems with the use of minimally invasive technique. Unfallchirurg. 2004;107:181-8.

48. Large TM, Kellam JF, Bosse MJ, Sims SH, Althausen P, Masonis JL. Locked plating of supracondylar periprosthetic femur fractures. J Arthroplasty. 2008;23(6 Suppl 1):115-20.

49. Gurava Reddy V, Krishna Mootha A, Chiranjeevi T, Kantesaria P, Kumar Ramireddy V, Reddy D. Bilateral symmetrical periprosthetic (mirror) fractures of knee fixed with dual plating technique. Int J Surg Case Rep. 2011;2:175-7.

50. Herrera DA, Kregor PJ, Cole PA, Levy BA, Jönsson A, Zlowodzki M. Treatment of acute distal femur fractures above a total knee arthroplasty: systematic review of 415 cases (19812006). Acta Orthop. 2008;79:22-7.

51. Tosounidis TH, Giannoudis PV. What is new in distal femur periprosthetic fracture fixation? Injury. 2015;46:2293-6.

52. Mortazavi SM, Kurd MF, Bender B, Post Z, Parvizi J, Purtill JJ. Distal femoral arthroplasty for the treatment of periprosthetic fractures after total knee arthroplasty. J Arthroplasty. 2010;25:775-80.

53. Keeney JA. Periprosthetic total knee arthroplasty fractures: revision arthroplasty technique. J Knee Surg. 2013;26:19-25.

54. Jassim SS, McNamara I, Hopgood P. Distal femoral replacement in periprosthetic fracture around total knee arthroplasty. Injury. 2014;45:550-3.

55. Rahman WA, Vial TA, Backstein DJ. Distal femoral arthroplasty for management of periprosthetic supracondylar fractures of the femur. J Arthroplasty. 2016;31:676-9.

56. Marsh JL, Slongo TF, Agel J, Broderick JS, Creevey W, DeCoster TA, Prokuski L, Sirkin MS, Ziran B, Henley B, Audige L. Fracture and dislocation classification compendium 2007: Orthopaedic Trauma Association classification, database and outcomes committee. J Orthop Trauma. 2007;21(10 Suppl):S1-133. 